\title{
ANALYSIS OF OPTIMUM OPERATING MODES OF POWER TRANSFORMERS UNDER OPERATING CONDITIONS
}

\begin{abstract}
Purpose. The study of parallel operation optimal modes of transformer equipment for a variety of operating conditions: same or different types of transformers, with or without reactive power flows. Methodology. Losses of energy in transformers make $30 \%$ of all losses. Therefore the choice of the economically justified parallel operation of transformers is effective action to reduce losses. Typically, in the calculations of reactive power flows in the transformers are not taken into account. It is interesting to analyze the optimal operating conditions of transformers with and without reactive power flows. Results. Calculations for transformers in distribution networks showed that the inclusion of reactive power flows in transformers significant impact on the calculated optimum regimes of transformers. References 9, tables 1, figures 2.
\end{abstract}

Key words: transformer equipment, parallel operation, optimal mode, reactive power, economically reasonable mode.

Приведены теоретические и практические положения оптимальности режимов работы трансформаторного оборудования на подстанции при их параллельной работе. Расчеты адаптированы для реальных условий эксплуатации для энергетики Украины. Библ. 9, табл. 1, рис. 2.

Ключевые слова: трансформаторное оборудование, параллельная работа, оптимальный режим, реактивная мощность, экономически целесообразный режим.

Introduction. In the power system of Ukraine in operation there are more than 100 high-voltage substations. At the same time in parallel operation can be up to four transformers at a substation. At the same time a substantial part of all electricity losses account for losses in transformers. Therefore, any cost-effective modes of transformers in substations are effective measures to reduce energy losses.

Theoretical studies provide enough valid recommendations for optimizing the operation of the transformer equipment based on catalog data. However, in actual use due to the aging of the individual elements of the transformer has to operate passport or experimental values. Experiments show that the values of no-load losses are most affected. When operating of transformer over 20 years loss value can be increased by $1.75 \%$ per year [1].

Analysis of recent investigations and publications. The problem of reducing losses in power transformers are engaged many scientists both domestic and foreign. In the end, it all comes down to the controversial problem of determining the optimal test operation of transformers in substations. The most widely used graphanalytic methods.

The optimization criterion of minimum active power losses presented in [2]. This approach is simple, gives good qualitative results in terms of operation but requires significant additions.

In [3] the criterion discussed above is designed to meet the reactive power flows. The proposed method improves the accuracy of calculations, bringing the theoretical calculations to real practical results in the field.

The optimization criterion of minimum energy loss is represented in [4]. This approach is different interpretations are today widely used in a variety of regulatory, scientific and practical materials. These criteria are effective, but require a sufficiently accurate and reliable de- termination of the time of inclusion in the work of power transformers.

Optimization criteria given transformer efficiency values presented in [5]. This complex combination of important characteristics of the transformer equipment requires precise calculations and studies [6], but clearly is of great scientific and practical interest.

Connection of optimization criteria and the period of service of power transformers are presented in [7].

Based on the literature and the wide statistical material can draw the following conclusion: any optimization criteria reflect the various aspects of efficient operation of power transformers. Addressing practical value criteria optimal performance of parallel-connected transformers is impossible without taking into account the reliability of power supply circuits, load profiles, on-time, the technical condition of the main power equipment (transformers, switches).

The goal of investigations is a comparative analysis of the optimal mode of parallel operation of transformer equipment for a variety of operating conditions and the same type for different types of transformers, with and without reactive power flows. As an optimization criterion used for at least the total active power losses. In view of the above, this problem is an actual scientific and practical problem $[6,8]$.

Theoretical principles. Most economic mode corresponds to a load of transformers, proportional to their nominal power [9].

Economic load distribution between parallel operating transformers occurs in the case of identical parameters. Unfortunately, in practice it is not always possible to achieve such a position that would have on each substation transformers are of the same type. This transformer load will be slightly different from the economic due to the occurrence of circulating currents.

(C) I.V. Khomenko, S.K. Berezka, I.V. Poliakov 
To determine the most economical mode of transformers built according to the loss of its power load of transformers $\Delta P_{\mathrm{t}}=f(S)$.

Consider the substation with $n$-parallel operating transformers of the same type. Power loss in the transformers of the same type, excluding the reactive power flows are according to the formula:

$$
\Delta P_{T}=n \cdot \Delta P_{0}+\frac{1}{n} \cdot \frac{\Delta P_{k} \cdot S^{2}}{S_{\text {rat }}{ }^{2}},
$$

where $n$ is the number of parallel operating transformers; $\Delta P_{0}$ is the no-load losses of the transformer; $\Delta P_{k}$ is the losses of short-circuit of the transformer; $S$ is the load power; $S_{\text {rat }}$ is the nominal power of the transformer.

Power losses in the transformers of the same type based on the reactive power flows are according to the formula:

$$
\Delta P_{T}=n \cdot\left(\Delta P_{0}+K \cdot Q_{F e}\right)+\frac{1}{n} \cdot \frac{\left(\Delta P_{k}+K \cdot Q_{C u}\right) \cdot S^{2}}{S_{\text {rat }}^{2}},
$$

where $K$ is the coefficient equal 0.08 ;

$$
Q_{F e}=\frac{I_{0} \cdot S_{r a t}}{100}
$$

is the reactive power losses in the steel, $I_{0}$ is the transformer no-load current;

$$
Q_{C u}=\frac{U_{k} \cdot S_{r a t}}{100}
$$

is the reactive power losses in the copper, $U_{k}$ is the transformer no-load voltage.

If installed at the substation transformers of different type or different power, they will have different losses $P_{0}$ and $P_{k}$. Use under these conditions of inequality can not be listed above. Then to select the number of parallelconnected transformers are the curves shown losses. They build on the coordinate plane for each transformer for several simultaneously [3].

The power loss for different types of transformers without taking into account the reactive power flows:

$$
\Delta P_{T}=\sum P_{0}+\sum P_{k} \cdot \frac{\sum S^{2}}{\sum S_{\text {rat }}^{2}} .
$$

The power loss for different types of transformers, taking into account the reactive power flows:

$$
P_{T}=\sum\left(P_{0}+K \cdot Q_{F e}\right)+\sum\left(P_{k}+K \cdot Q_{C u}\right) \cdot \frac{\sum S^{2}}{\sum S_{r a t}^{2}} .
$$

If the substation is installed $\mathrm{n}$ three-winding transformers with capacities of all three windings, equal to the nominal capacity of the transformer $S_{T}$, it is necessary to postpone the loading $S_{S U B}$ substation on the $x$-axis:

$$
\mathrm{S}_{s u b}=\sqrt{\left(\mathrm{S}_{L V}^{2}+\mathrm{S}_{M V}^{2}+\mathrm{S}_{H V}^{2}\right) / 2} \text {. }
$$

Indeed, in this case, the expression takes the form:

$$
\Delta P_{s u b}=n \cdot \Delta P_{0}+\frac{R_{100}}{n} \cdot\left(\frac{S_{H V}^{2}+S_{M V}^{2}+S_{L V}^{2}}{U_{\text {rat }}^{2}}\right),
$$

$$
R_{100}=\Delta P_{k} \cdot U_{\text {rat }}^{2} /\left(2 S_{T}^{2}\right) .
$$

Substituting this relation in (8), together with (7) we obtain

$$
\Delta P_{\text {sub }}=n \cdot \Delta P_{0}+\frac{P_{k}}{n} \cdot\left(\frac{S_{s u b}}{S_{T}}\right)^{2} .
$$

In those cases where a low voltage output winding (LV) of the transformer is 50,40 , or $25 \%$ of nominal, R100 resistance must be correspondingly increased in 2, 2.5 or 4 times, after which it will be equal to the resistance given winding LV. If by «a» denote the coefficient of resistance reduction, in general terms the value of the dummy load of three-winding transformers can be represented as follows:

$$
S_{s u b}=\sqrt{\left(a S_{L V}^{2}+S_{M V}^{2}+S_{H V}^{2}\right) / 2} .
$$

Calculations. As initial data for calculation examples we use the passport data of transformers ТРДН$80000 / 110$ and ТРДН-63000/110 of life of 32 and 37 years, respectively (Table 1). The calculations were performed in the environment MathCad.

Table 1

Passport data of transformers

\begin{tabular}{|l|c|c|}
\hline & ТРДН 80000/110 & ТРДН-63000/110 \\
\hline Rated power $S_{\text {rat }}$, MVA & 80 & 63 \\
\hline $\begin{array}{l}\text { Short-circuit } \\
\text { losses } \Delta P_{k}, \mathrm{MW}\end{array}$ & 0.310 & 0.245 \\
\hline $\begin{array}{l}\text { No-load } \\
\text { losses } \Delta P_{0}, \mathrm{MW}\end{array}$ & 0.0696 & 0.06 \\
\hline No-load current $I_{0}, \%$ & 0.5 & 0.5 \\
\hline $\begin{array}{l}\text { Short-circuit } \\
\text { voltage } U_{\mathrm{K}}, \%\end{array}$ & 10.5 & 10.5 \\
\hline$K$ & 0.08 & 0.08 \\
\hline
\end{tabular}

\section{Example 1.}

We optimize the work of similar ТРДН-80000/110 $n=3$, without taking into account the reactive power flows.

Total losses, depending on the number of parallel operating transformers $(n)$ and the load $(S)$ are defined by the expression (1).

Load range $S=0 \ldots 110$. Optimization zones are shown in Fig. 1,a.

Example 2.

We optimize the work of similar ТРДН-80000/110 $n=3$, taking into account the reactive power flows.

Reactive power losses in the steel are determined by the expression (3) $Q_{F e}=0.4 \mathrm{MVAr}$, and in copper - by the expression (4) $Q_{C u}=8.4$ MVAr.

Total losses, taking into account the reactive power losses are determined by the expression (2).

Load range $S=0 \ldots 100$. Optimization zones are shown in Fig. 1,b.

where $R_{100}$ is the rated the active resistance of the coil, which is equal to the power $100 \%$ of $S_{T}$ : 

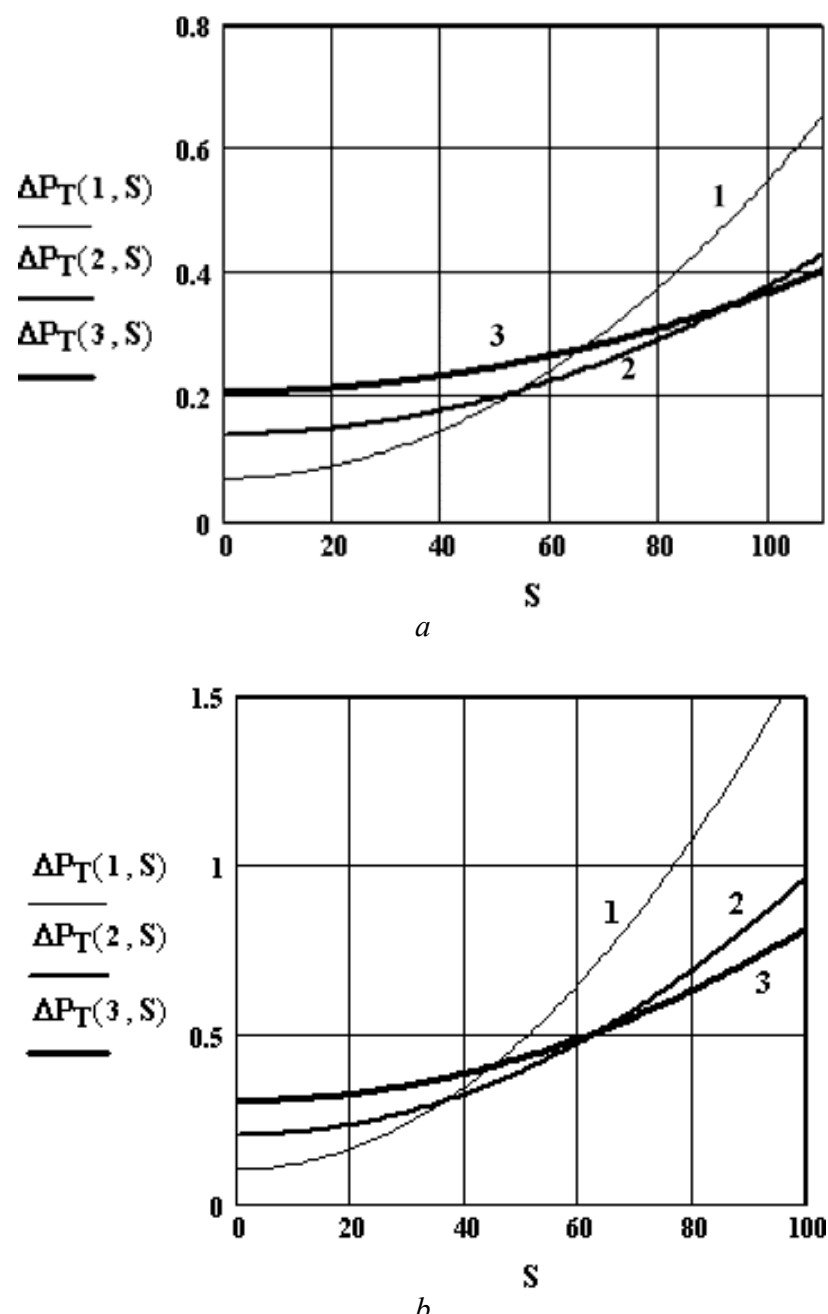

Fig. 1. Dependence of power losses on the load and the number of similar transformers ТРДН-80000/110

( 1 - one transformer operates, 2 - two

transformer operate; 3 - three transformers operate): $a$ - excluding the flow of reactive power;

$b$ - taking into account the flow of reactive power

\section{Example 3.}

We optimize the diverse ТРДН-80000/110 and ТРДН-63000/110 transformers operation excluding reactive power flows.

$$
\Delta P_{T 1}(S):=\Delta P_{0,1}+\frac{\Delta P_{k 1} \cdot S^{2}}{S_{\text {rat } 1}^{2}}-\text { losses in ТРДН- }
$$

$80000 / 110$

$$
\Delta P_{T 2}(S):=\Delta P_{0,2}+\frac{\Delta P_{k 2} \cdot S^{2}}{S_{r a t 2}^{2}}-\text { losses in ТРДН- }
$$

$63000 / 110$

Total losses are determined by (5).

Load range $S=0 . .60 \mathrm{MVA}$. Optimization zones are shown in Fig. 2, $a$.

Example 4.

We optimize the diverse transformers ТРДН80000/110 and ТРДН-63000/110 taking into account the reactive power flows.

Reactive power losses in the steel and copper of the indicated transformers are determined by (3) - (4): $Q_{F e 1}=0.4 \mathrm{MVAr}, Q_{C u 1}=8.4 \mathrm{MVAr}, Q_{F e 2}=0.315 \mathrm{MVAr}$, $Q_{C u 2}=6.615$ MVA.

$$
\Delta P_{T 1}(S):=\left(\Delta P_{0,1}+K \cdot Q_{F e 1}\right)+\frac{\left(\Delta P_{k 1}+K \cdot Q_{C u 1}\right) \cdot S^{2}}{S_{\text {rat } 1}^{2}} \cdot-
$$

losses in ТРДН-80000/110,

$$
\Delta P_{T 2}(S):=\left(\Delta P_{0,2}+K \cdot Q_{F e 2}\right)+\frac{\left(\Delta P_{k 2}+K \cdot Q_{C u 2}\right) \cdot S^{2}}{S_{r a t 2}^{2}} .-
$$

losses in ТРДН-63000/110,

Total losses are determined by (6).

Load range $S=0 . . .40$ MVA. Optimization zones are shown in Fig. $2, b$.
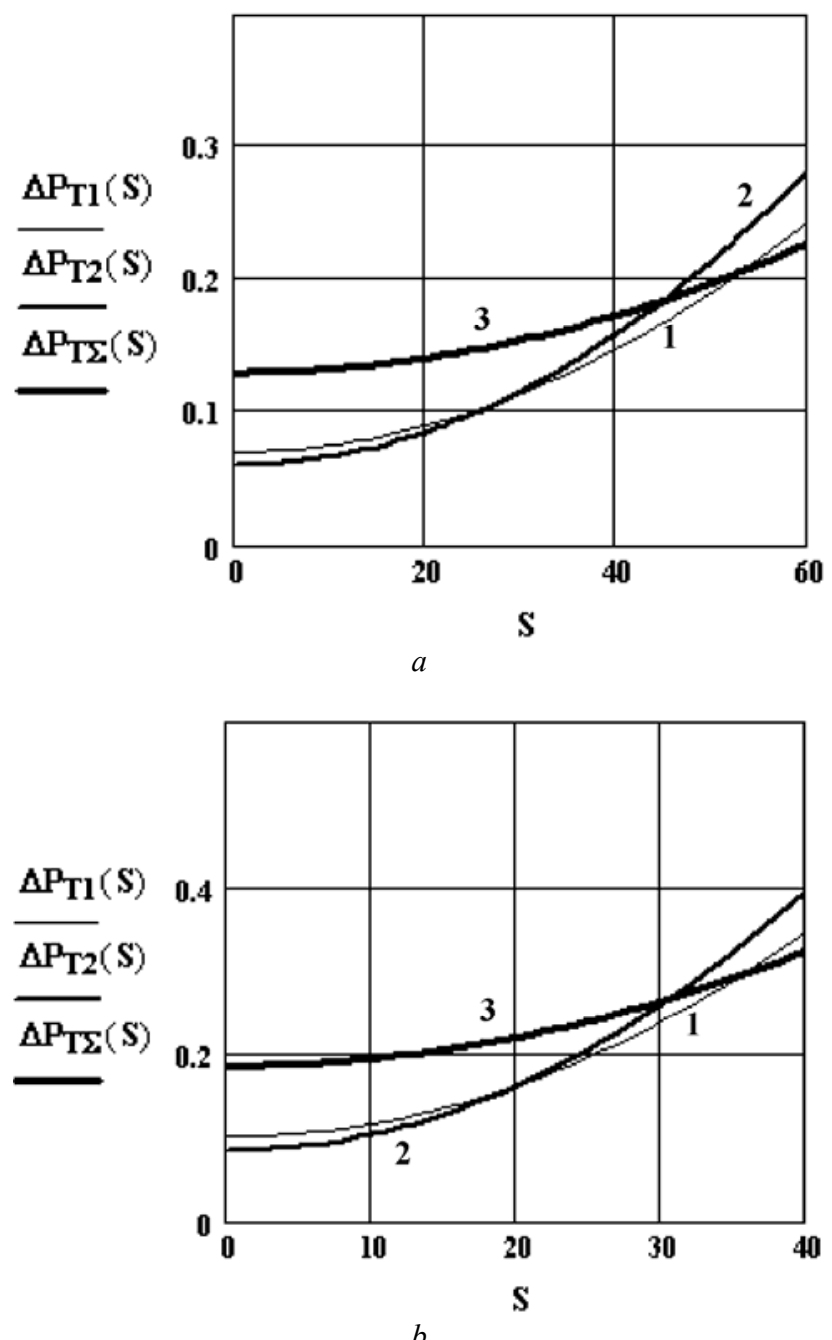

Fig. 2. Dependence of power losses in transformers of different types of loads ( 1 - transformer ТРДН-80000/110 operates, 2 transformer ТРДН-63000/110 operates; 3 - both transformers operate): $a$ - excluding the flow of reactive power; $b$ - taking into account the flow of reactive power

\section{Conclusions.}

As a result of the calculations optimization zones of transformer equipment of the substation at their parallel operation are determined. The calculations were performed for the actual operating conditions: for the same type and different types of transformers, with and without reactive power flows.

Comparative analysis shows errors due to the use of certain optimization techniques that ultimately determine the admissibility of their use. Maximum error due to the 
difference of catalog and passport data for the cases examined, does not exceed $20 \%$.

\section{REFERENCES}

1. Korotkov V.V., Kozlov A.B., Korotkov A.V. Quantification of losses depending on the idling of power transformers lifetime. Proceedings of the Ivanovo State Power University, 2007, iss.8, pp. 351-356. (Rus).

2. Radkevich V.N., Trutnikov A.L. On the choice of optimization of the criterion power transformer. Energy and management, 2004, no.4-5, pp. 32-33. (Rus).

3. Filatov A.A. Obsluzhivanie elektricheskih podstantsiy operativnyim personalom [Service of electric substations by operation personnel]. Moscow, Energoatomisdat Publ., 1990. 304 p. (Rus).

4. Metodyka vyznachennia neratsionalnogo vykorystannia palyvno-energetychnyh resursiv. [Method of determining the irrational (inefficient) use of energy resources]. Kyiv, NAER Publ., 2009. 134 p. (Ukr).

5. Fursanov M.I. Metodologia i praktika opredelenia i analiza poter elektroenergii. Autoref. diss. dokt. tekhn. nauk [Methodology and practice of identification and analysis of power losses in electric networks of power supply. Abstracts of doct. tech. sci. diss.] Minsk, 2002. 39 p. (Rus).

6. Gonchar A.A. On criteria for optimization of the power transformer. Energy and management, 2004, no.2, p. 45. (Rus).

7. Balabin A.A Razrabotka metodiki raschete poter elektroenergii v magniti provodah dlitelno ekspluatiruyuschihsia trans- formatorov. Autoref. diss. kand. tekhn. nauk [Development of the method of calculating energy losses in magnetic wires long maintained power transformers. Abstracts of cand. tech. sci. diss.]. Orel, 2009. 18 p. (Rus).

8. Kutsenko G.F., Parfenov A.A. Selecting distribution transformers $6-10 \mathrm{kV}$ at a minimum electricity losses. Energy efficiency, 2001, no.11, pp. 18-19. (Rus).

9. Idelchik V.I. Elektricheskie sistemy $i$ seti: Uchebnik dlia vuzov [Electrical Systems and Grids: Textbook for high schools]. Moscow, Energoatomisdat Publ., 1989. 592 p. (Rus).

Received 01.09.2016

I.V. Khomenko ${ }^{1}$, Candidate of Technical Science, Associate Professor,

S.K. Berezka ${ }^{1}$, Candidate of Technical Science,

I.V. Poliakov ${ }^{1}$, Candidate of Technical Science, Associate

Professor,

${ }^{1}$ National Technical University «Kharkiv Polytechnic Institute», 21, Kyrpychova Str., Kharkiv, 61002, Ukraine,

e-mail: igor.v.khomenko@gmail.com, serg.berezka@gmail.com

How to cite this article:

Khomenko I.V., Berezka S.K., Poliakov I.V. Analysis of optimum operating modes of power transformers under operating conditions. Electrical engineering \& electromechanics, 2016, no.6, pp. 70-73. doi: 10.20998/2074272X.2016.6.12. 